\title{
Improving schools through collaboration: a mixed methods study of school-to-school partnerships in the primary sector
}

\author{
Daniel Muijs* \\ University of Southampton, UK
}

The principle of schools collaborating to improve is one that has seen growing interest in recent years, and there is emerging evidence that in particular collaboration between high and lower performing schools can be an effective school improvement method. However, this evidence relates primarily to secondary schools, and little research has been conducted on the factors that could make collaboration more or less effective. In this study we specifically looked at partnerships between low and high performing primary schools, in which high performing schools acted as supporters to low performing partner schools. A mixed methods approach was used. A quasi-experimental quantitative study was conducted to ascertain the relationship between partnership and pupil attainment using data from the National Pupil Database. This was followed up by case studies of nine partnerships. Findings showed that there was a positive relationship between partnership and pupil attainment at Key Stage 2, and that successful partnerships were characterised by intensive interventions focused on teaching and learning and leadership.

Keywords: school improvement; collaboration; mixed methods; pupil attainment

\section{Introduction}

The principle of schools collaborating to improve is one that has seen growing interest in recent years, as the limitations of top-down reform efforts and individual school improvement have become apparent. The former tend to be insufficiently adapted to context and therefore often show patchy results, while the latter lack scale and impact on the broader environment or system. Collaboration and networking are seen as having specific advantages for school improvement, which

*University of Southampton, Southampton Education School, Highfield Campus, Southampton SO17 1BJ, UK. Email: d.muijs@soton.ac.uk 
include allowing schools to pool resources and improve the provision of professional development (Lieberman, 2000), allowing schools to plug 'structural gaps' in their own expertise and skills (Muijs, West \& Ainscow, 2010), and allowing them to develop mutual support mechanisms and overcome an overly inward-looking approach (Wohlstetter, Malloy, Chau \& Polhemus, 2003). Collaboration between schools also allows them to take ownership of the change process, which is often a problem in large-scale reform efforts (Muis et al., 2010). In recent years, education systems have therefore invested significant resources in developing collaborative approaches to school improvement. In England, a variety of initiatives have taken place, such as the Federations programme, while recently Academies have started to be organised in chains where a group of schools is run by the same sponsor. In the USA we have seen the emergence of Charter Management Organisations running networks of Charter schools, and many other school networks (such as the League of Professional Schools) exist. In continental Europe this trend is apparent as well. In Flanders, schools are required to become part of local communities of schools, while in the Netherlands they are encouraged to form collaborations with not just other schools but community organisations and other public services. Other countries have seen similar initiatives (Chapman \& Muijs, 2013).

Theoretically, there are a number of reasons why collaboration might be a successful school improvement strategy. Muijs, Chapman, Ainscow \& West (2011) identified four main theoretical positions advocating interorganisational collaboration and networking: constructivist organisational theory, the theory of social capital, 'New Social Movements' theory, and Durkheimian network theory. According to constructivist theory, organisations are sense-making systems creating shared perceptions and interpretations of reality. This means that each organisation will to a certain extent have its own unique perception of reality, albeit one that is anchored in its context. This sense-making function is essential for organisations to function effectively, but runs the risk of becoming myopic, in that the organisation may become closed to external influences. It is this myopia that can be addressed through networking with other organisations or other external partners that can provide access to a complementary cognition. Social capital theory takes a more instrumental view, stressing the ways networking allows organisations to harness resources held by other actors and increase the flow of information in a network. New social movements is a term coined to describe the novel forms of social action (such as the environmental movement) that developed from the 1960s onwards. These are seen as far more fluid than traditional social movements (such as Trade Unions), and are characterised not so much by single insurrections as by a series of events, and by organisations/people linked together in various more or less formal and transient patterns. Hadfield (2007) claims that networks of schools can be seen as such, displaying as they do a number of these characteristics, such as transience, complexity and the need to build up new identities for the network that are distinct from those of the individual schools. The dominant role of activist leaders can likewise be seen in many school networks. This perspective seems most appropriate for networks that have developed bottom-up through autonomous school action. 
Durkheimian theory in turn sees networking as key to combatting anomie which can result from a lack of strong ties and a disconnect between actors' ideologies and the behaviours they are forced to engage in, often a problem for schools facing challenging circumstances. All of these perspectives, then, suggest that collaboration and networking could benefit schools, though the relative validity of these theoretical perspectives has only been explored to a limited extent in the literature, with most studies, in so far as they are theoretically grounded, tending to address one particular perspective only.

However, despite policies promoting partnership and networking and the theoretical support for engaging in school-to-school collaboration, the impact of these arrangements on student outcomes has not been subject to much rigorous study, and the overall evidence of the impact of networking and collaboration on pupil outcomes is limited. Some evidence of impact comes from a systematic review of 14 studies carried out by the Networked Learning Group and CUREE (2005), showing positive impacts on pupil outcomes in nine studies, and positive impacts on teachers in 11. Nine studies reported whole school benefits, such as increased professional development or the emergence of a learning culture, while nine studies reported positive impacts on parental involvement. Where positive benefits were reported, they accrued to the majority of schools in the partnerships, regardless of performance levels. Impacts on students were mainly in the areas of achievement of targeted groups such as pupils at risk or pupils with SEN, while impact on teachers took the form of gains in teacher knowledge and skills, which were in some cases explicitly linked to changes in behaviour. There is also some evidence from evaluations of individual programmes, such as the SSAP run by the Specialist Schools Trust which partnered low achieving schools with 'lead' schools that supported them and showed positive outcomes for the low achieving schools in the study (Chapman \& Allen, 2005), and the Federations programme, where respondents reported positive benefits from their network activities in a number of Federations of schools, though firm evidence of impact on school effectiveness was not universal (Lindsay et al., 2007). A review of the work of Networked Learning Groups in England found patchy evidence of impact, with examples of improvements in areas such as pupil attainment, teacher motivation and leadership capacity in networks, but no firm evidence of a global impact (Hadfield, Jopling, Noden, O'Leary \& Stott, 2006). These differential effects were not linked to the performance levels of the schools. Becoming part of a Federation and support from headteachers designated as National or Local Leaders of Education were considered to be effective strategies in improving attainment in underperforming schools in the City Challenge programmes, particularly in London, while working with other schools was considered a key factor in improving so-called 'coasting' schools. However, merely sharing data on similar schools (through the Family of Schools programme) was not particularly effective (Hutchings et al., 2012).

Some of these mixed findings may, of course, be the result of differential implementation of network activities. As with any other school improvement intervention collaboration is unlikely to be a panacea for improvement, and conditions and 
strategies will need to be in place for it to be successful. In this respect, the importance of leadership support, developing a clear set of shared goals, finding the right partner, building trust, ensuring ownership in all partnership schools, developing collective responsibility, and the provision of time for key staff involved in partnership work have been highlighted (Muijs et al., 2011; Rudd, Lines, Schagen, Smith \& Reakes, 2004; West, 2010). Leadership capacity to support networking has also been reported to be a key to successful partnerships (Hadfield \& Chapman, 2009). However, in many cases the lack of a firm link between studies of processes of collaboration and studies of outcomes of collaboration mean that these findings have to be seen as tentative. The value of networking and collaboration when compared to other forms of organisational development has also been questioned by a number of authors, with benefits seen to be slow to emerge and uncertain, and networking tending towards overcomplexity if not focused on a small number of goals or practices (Huxham \& Vangen, 2000).

The lack of quantitative evidence of impact led Chapman \& Muijs (2013) to conduct a study of the impact of networking and collaboration, looking in particular at Federations of schools, a form of collaboration between secondary schools in England. Using the National Pupil Database (a database of all English pupils) to create a quasi-experimental design, it was shown that pupils in Federation schools significantly outperformed pupils in matched comparison schools. However, this was not the case in all types of Federation, being largely limited to those Federations consisting of a high and one or more low performing schools (so-called 'Performance Federations'). The gains were strongest in the low performing schools, but modest improvements were also present in some high performing schools. A follow-up study (Chapman \& Muijs, 2014) confirmed these findings, and also showed that those 'performance federations' that had stronger structuring of their collaboration showed stronger gains. The follow-up study also used telephone interviews to gather some of the reasons for collaborating and some of the perceived benefits, but this qualitative component was limited in scope, and did not allow sufficient exploration of reasons for the effectiveness of collaborations between stronger and weaker schools, or for the finding of differential effectiveness of individual performance federations. Furthermore, though Federations exist in the primary sector, sample size considerations meant that the study was limited to secondary schools, meaning that we do not have as much evidence on whether the concept of strong and weaker schools collaborating can have as positive an impact in the primary as in the secondary sector. This is a major weakness, as school effectiveness research has typically shown that school effects accrued in early years and primary education persist over time (Sammons, 2010) and that early intervention is key to improving long-term outcomes for students from disadvantaged backgrounds in particular (Hall et al., 2013).

In this study we therefore aimed to further explore school-to-school collaboration as a vehicle for school improvement, focusing on partnerships between stronger and weaker schools, but extending previous work by looking at: 
- Collaboration between primary schools;

- Non-federation collaboration;

- More extensive study of elements that make collaboration more or less successful.

This leads us to the following research questions:

1. Is collaboration between high and low performing primary schools related to improvements in pupil attainment in either or both type of schools?

2. What activities are related to effective collaboration between low and high performing primary schools?

3. What factors can explain any differences in effectiveness of collaboration between low and high performing primary schools?

In addition, it is hoped that this study will also shed some light on the validity of the theoretical perspectives outlined above.

\section{Methods}

To look at these questions, we were able to draw on a study of a project that was specifically designed to improve primary schools perceived as ineffective or failing in one local authority in England. The authority in question is an urban area, and is in the top quartile of most deprived Local Authorities in England according to the Index of Multiple Deprivation. Approximately three quarters of the population is White British. Educational attainment is below the national average, and a relatively large proportion of local primary schools are deemed to be failing or underperforming.

In order to help combat this perceived educational underperformance, the authority's school improvement service instigated a programme in which low and underperforming primary, junior and first schools would be partnered with high performing schools, with a view to the latter supporting the former. The authority acted as a broker, identifying underperforming schools and their potential partner schools, and arranging initial contacts between the leadership teams of the partnered schools. The local authority also monitored the partnerships and their progress. Each underperforming school was partnered with one supporting school, though the latter sometimes supported more than one partner. The partnerships could last from six months onwards. Supporting schools had to be high performing relative to intake, and show strong leadership, with the Headteacher being either a Local or National Leader of Education (a designation of quality). In total, 37 schools were involved in a total of 17 networks. Twenty schools were supported by 17 supporting schools (some supporting more than one). Both supporting and supported schools were included in the analyses, which will be presented separately for supported and supporting schools. 
To answer our research question we used a mixed methods approach involving a quasi-experimental quantitative design to look at impact and qualitative case studies of both supporting and supported schools within the partnerships to study processes.

\section{Quantitative study}

Data from the pupil-level annual school census (PLASC) and the national pupil database (NPD) were requested from and provided by the Department for Education (DfE) to examine performance measures controlled for student background over time.

In order to examine the relationship between being part of a school partnership and student attainment, a quasi-experimental design was developed in which each partnership school was matched to a school as similar as possible on key characteristics in the two years prior to joining the partnership. The datasets were used to match schools on a number of criteria. As the strongest predictors of attainment are student intake characteristics (Strand \& Demie, 2002), the comparison group was matched based on prior attainment (KS1), ethnicity, gender and social disadvantage (FSM eligibility) and Special Educational Needs status, as well as location (institutions were selected from authorities that are reasonable statistical neighbours to the Local Authority in question). The comparison groups were constructed so that they contained an approximately equal number of students to the sample schools. Two comparisons were calculated, one for supporting schools and one for supported schools, so each school in each of these two groups was paired with a comparator school in this way. Data were then separately analysed for supporting and supported schools and their respective comparators.

Obviously, this set of variables does not represent the full range of factors on which schools can differ. Factors not measured in the National Pupil database, such as quality of leadership, may account for some of the differences found. Furthermore, no schools could be matched identically on these criteria. However, as close a match as possible was sought in all cases using propensity score matching methods. This was done by calculating a propensity score for each school. This score is the probability that a school would be part of the treatment group given it has characteristics $\mathrm{X}$ (e.g. being of a certain size). A logistic regression analysis is conducted to estimate the probability that a school will be in the treatment group with the criteria given above used as the predictor variables. This score is calculated for all schools, both those in the treatment and those not in the treatment group. We then used nearest neighbour matching to match each school in the treatment group to the school which had the most similar propensity score. This method, which aims to ensure that schools are as similar as possible on key variables (in this case the seven characteristics outlined above) is particularly suitable in those cases where no identical matches can be found (as is the case here). No statistically significant differences were found between partnership and control schools on any of 
these variables following matching. We ensured that comparison schools were not engaged in extensive collaboration with other schools through brief telephone interviews.

The outcome variable, attainment, was measured using KS2 test results at the individual pupil level. Two-level multilevel statistical methods were used for the analyses, taking into account that pupils were nested in schools. This method divides the variance in outcomes between the different hierarchical levels at which the data are nested. In this case there were two such levels, individual pupils and the schools they went to (the classroom level is not present in the National Pupil Database).

\section{Qualitative study}

In addition to this quantitative study, we conducted a series of qualitative case studies in both supporting and supported schools.

Nine partnerships and 18 schools were randomly selected to be cases for the qualitative component of the study. Random selection was chosen as qualitative data collection started before completion of the quantitative analyses, so purposive sampling on the basis of whether or not partnerships had been successful, though desirable, was not possible due to this data not yet being available on sample selection. In these circumstances random selection appeared to offer the greatest probability of selecting a varied range of partnerships. Of the nine partnerships eventually selected, in five the supported school showed significant improvement while the supporting school showed no change (partnership type I), in two both supporting and supported schools showed significant improvement (partnership type II), while in the final two no significant changes were found in either school (partnership type III). Table 1 depicts the case study sample.

In these schools interviews were conducted with senior leaders, middle level leaders, governors and teachers in both supporting and supported schools, to provide in-depth information needed to gain an understanding of processes involved. In each school, semi-structured interviews were undertaken with the head and with between one and three other staff members and a school governor.

Data from the case studies consisted of 49 interviews. Interviews were between 23 and 68 minutes in length. Data were analysed in three phases:

School-level analysis. The evidence for each school was analysed in order to determine possible links between contextual factors and perceptions of collaboration, using a coding system corresponding to emerging themes (Miles \& Huberman, 1994). An audit trail was created in order that claims about the relationship between practices and outcomes could be subjected to scrutiny (Schwandt \& Halpern, 1988).

Network- level analysis. We then carried out a cross-site analysis of the accounts of practice in relation to the overall research questions, in order to study links between responses in supported and supporting schools in the network. 
In a final phase cross-level analysis was conducted to tease out overarching themes. In this way, conclusions were reached that are both valid and relevant. In addition, interviewees from the participating schools were invited to comment on the final report before submission.

\section{Results}

\section{Is there a relationship between partnership and student outcomes?}

In order to examine the first research question we compared partnership schools with their comparators. The results are shown in Tables 1-3. Key Stage 2 points scores (a measure based on the end of primary school national assessments in England) were used as the dependent variable. Data are given for the three years of the programme and the baseline year (the year prior to the start of the programme).

As is characteristic of multilevel modelling approaches the first model is a socalled empty one, with no independent variables included, to provide us with a baseline model.

As we can see in Table 1 , between $15 \%$ and $20 \%$ of the variance in pupil outcomes is situated at the school level, the remainder at the pupil level. School level variance was somewhat larger in the supported (and comparator) sample than in the supporting (and comparator) sample.

In the second model we added pupil level predictors, such as eligibility for Free School Meals (a measure of poverty) and the child's score on the IDACI index, an area-based statistic which is an indicator of poverty factors relating to children in the area; gender; special needs status (three dummy variables were created for this four-category variable: school action, school action plus and statemented in order of severity of needs, with no SEN being the reference category); ethnicity (five main groups were found in the sample, so four dummy variables were created. Black was

Table 1. Case study sample showing supporting and supported schools (schools showing significant improvement in pupil attainment in italics)

\begin{tabular}{lll}
\hline & Supporting school & Supported school \\
\hline Partnership 1 & School A & School F \\
Partnership 2 & School B & School K \\
Partnership 3 & School C & School L \\
Partnership 4 & School D & School M \\
Partnership 5 & School E & School N \\
Partnership 6 & School F & School O \\
Partnership 7 & School G & School P \\
Partnership 8 & School H & School Q \\
Partnership 9 & School I & School R \\
\hline
\end{tabular}




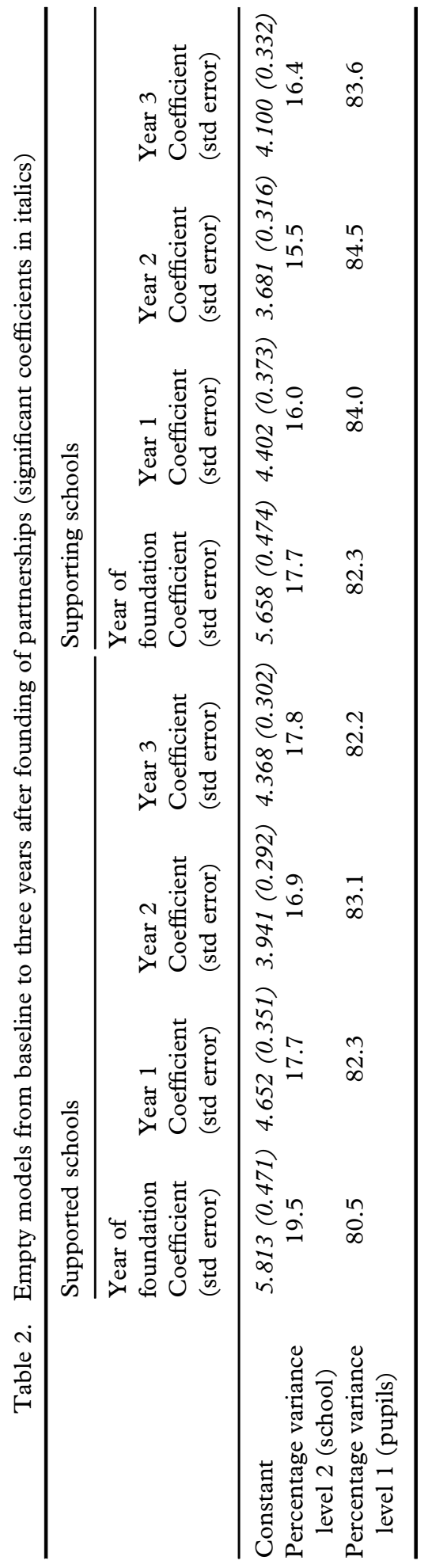




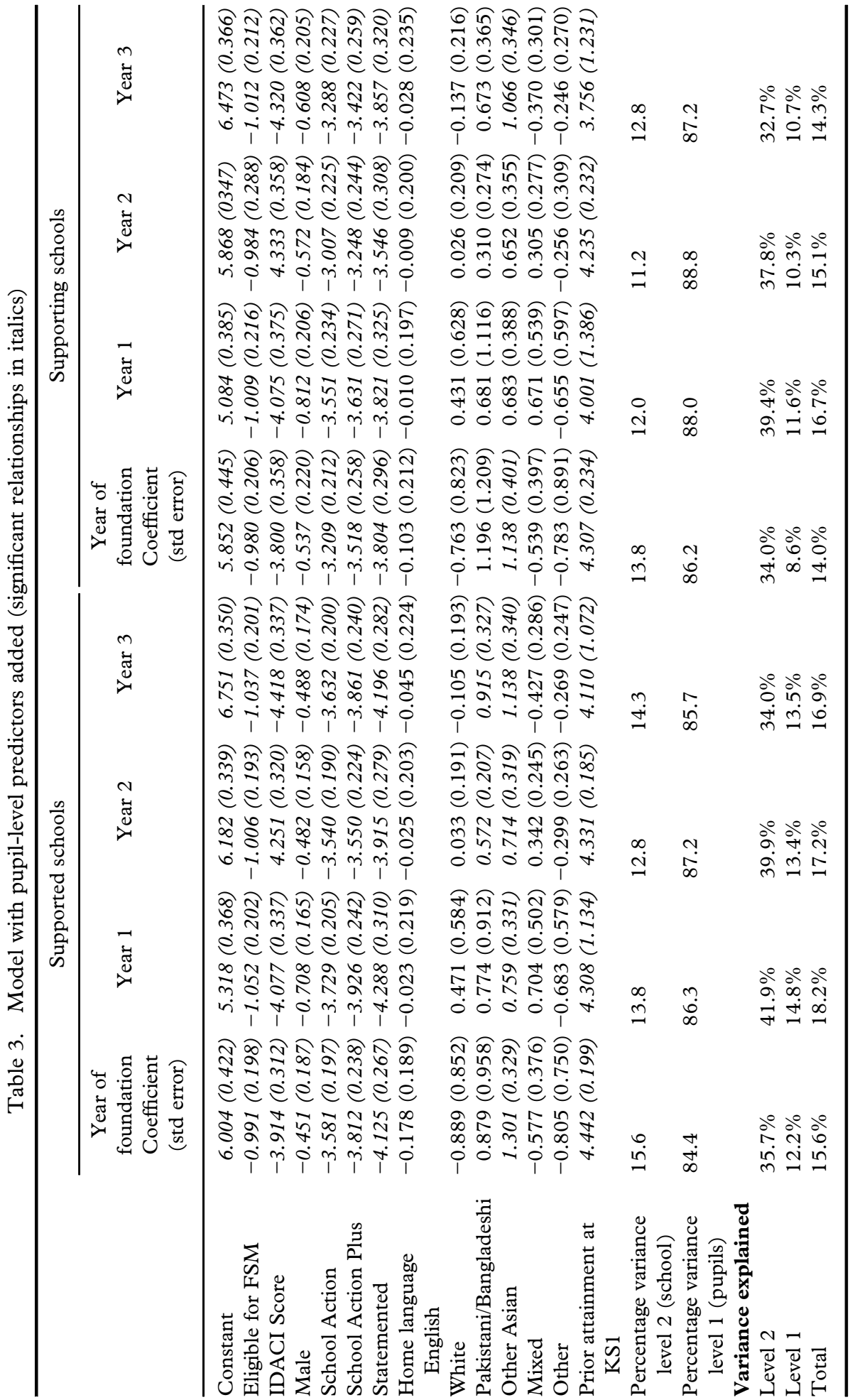









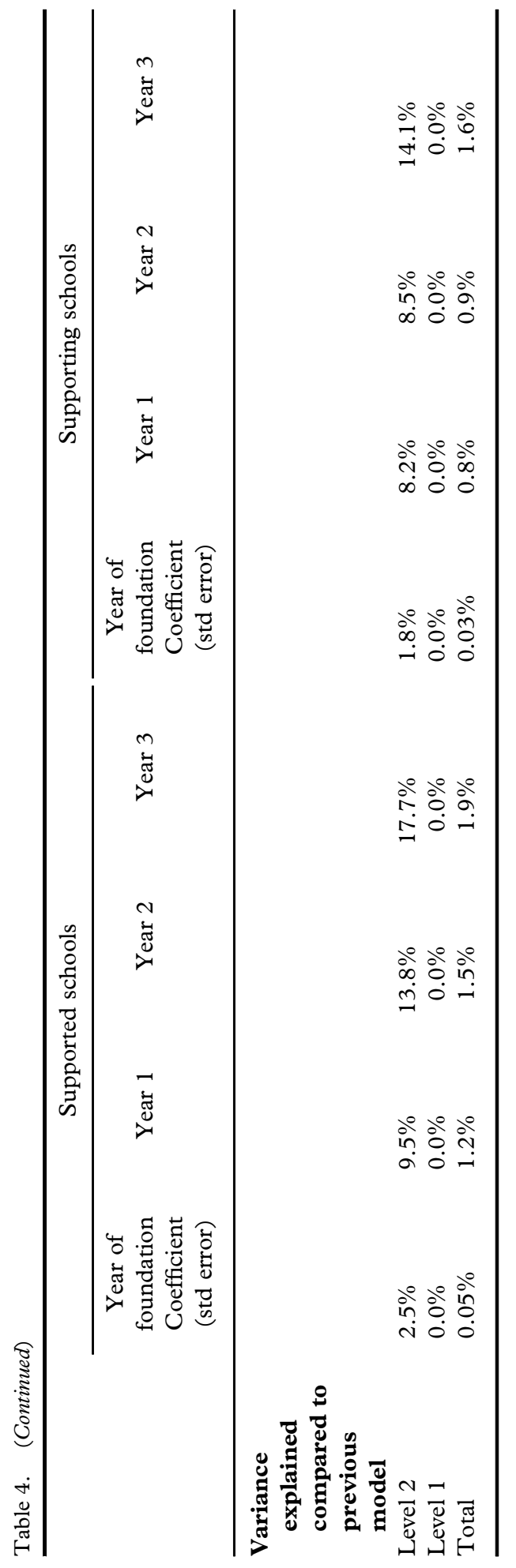


the reference category); language spoken at home (English or other); and prior attainment at Key Stage 1 (the first two years of primary school).

Table 2 shows that pupil intake characteristics explain a significant proportion of variance in pupil attainment at both the school and pupil levels. Overall, they explain up to $18.2 \%$ of total variance in the supported and comparator schools, and up to $16.7 \%$ in the supporting and comparator schools. At the school level they explain up to $42 \%$ of variance in the supported and up to $39 \%$ of variance in the supporting schools, demonstrating that much of the difference in performance between schools is down to differences in their intake. Prior attainment, measures of social background (FSM, IDACI) and being identified as having special educational needs were the main predictors of outcomes in both samples.

In the final model we added partnership, a dummy variable that indicated whether or not the school was part of the partnership or was a comparison school.

The analyses reported in Table 3 show that pupils in partnership schools outperformed their peers in matched comparison schools, with the strength of the relationship growing over time, which suggests greater improvement in partnership schools than in matched comparators. The relationship was, however, a lot stronger in the supported than in the supporting schools. In the supported schools the relationship became statistically significant in Year 2, and explained between 9.5 and $18.7 \%$ of school level variance, while in the supporting schools the relationship was only statistically significant in Year 3, and explained between $8.2 \%$ and $14.1 \%$ of school level variance. This suggests that the relationship is more beneficial for the supported schools, though it does not appear to have any negative impact on supporting schools, and may at best show a small positive relationship between supporting in a partnership and student outcomes.

\section{What did effective Partnerships do?}

Phase 1 showed that overall there was a positive relationship between being part of a partnership and attainment. However, it did not tell us anything about possible reasons for this. Furthermore, interrogating the data more closely it was clear that the overall positive effect was not replicated in all individual partnerships, with some showing no improvement. In phase 2 we therefore used the case study data to look in more depth at processes that could provide some, albeit tentative, explanations. We focused on what effective partnerships do, what conditions need to be in place for effective collaboration, and what problems might be involved.

What was very apparent from the case study data was that effective partnership working entailed intensive intervention by the supporting school. Headteachers and other members of senior management were typically involved in the partnership work, and often spent a significant amount of time in the supported school. A lot of the successful models revolved around doing very concrete delineated activities, based on clear and limited goals: 'We sat down and identified clearly what my staff could do for her staff (Head, supporting school D, partnership 4, type I). 
This intensive action was characterised by intervention in three main areas: leadership development, development of teaching and learning approaches, and generating quick wins.

Leadership development. Leadership capacity was an issue in many supported schools, and was addressed through the partnerships in a number of ways, focusing primarily on mentoring of new leaders, optimising leadership structures and providing emotional support for leaders.

Mentoring was often used in the partnerships, especially where the supported school had a new or inexperienced head or senior management team. In one partnership, for example: 'We helped appoint the new deputy head, and my deputy, who is experienced, mentored her, and smoothed off those edges of youth and enthusiasm, so she did not rub people up the wrong way' (Head, supporting school B, partnership 2, type I). Coaching of leaders in supported schools was also common. Clarifying the role of the head, and in particular what tasks needed delegating or distributing could be important when supporting newer heads.

A second common intervention was clarifying leadership systems and structures: 'We set up systems. This is the structure of the whole school. There is a school improvement plan, and from that comes every meeting, every piece of monitoring ... everything is simplified' (Head, supporting school A, partnership 1, type I). Clear protocols and guidelines were key, and in many cases supporting schools aimed to make processes more efficient: 'Most people are working hard. That's not the problem. Often though people are putting their energy into the wrong thing' (Deputy Head, supporting school A, partnership 1, type I).

In many cases these targeted interventions were combined with more general emotional support, where headteachers developed strong relationships with senior staff in the supported school, as in the struggling schools heads and senior managers could feel isolated: 'No one in your own staff understands what it's like being a head, so having someone to talk to really helps' (Head, supported school O, partnership 6, type II). Heads often met: 'She comes in and we have a chat about things, I can bounce ideas off her' (Head, supported school M, partnership 4, type I).

Developing teaching and learning. A focus on teaching and learning was usually at the heart of successful improvement. Weaknesses in this area were identified as a key issue in most of the supported schools, often linked to a lack of professional development opportunities. In one school, staff had not had any real CPD since the National Strategies training: 'The school went through a period of being perceived as very successful, but as a result became inward looking. So we never really did CPD. But what was $O K$ ten years $O K$ is not necessarily $O K$ now. So what we've done is slowly open the doors, and the partnership has been key to that' (Head, supported school J, partnership 1, type I). 
A range of strategies were used to improve the quality of teaching and learning, with coaching, joint lesson planning, mutual observation, and a focus on assessment in particular characterising interventions in the most successful partnerships.

One school used a very direct form of coaching to improve the quality of teaching, going so far as in some cases having the coach in the classroom alongside the teacher, and this was seen as creating a cultural change: 'That cultural change, from just monitoring, to saying, we are monitoring, but we are supporting you through the coaching, not just saying what is wrong but building in the support and development is very powerful' (Head, supported school P, partnership 7, type II). A model used successfully in one partnership was to start with the reasons for needing to change classroom practise, followed by observation, and then looking at data and planning.

Working on joint lesson planning, where teachers from the two schools worked together, to develop teaching activities or put in place behaviour management strategies for example, had also shown promising results. Mutual observation was frequent: 'We put together a package that was a combination of outreach work from $X$ staff to us, and our staff going to school $Y$, to look at good practise and raise aspirations' (Head, supported school L, partnership 3, type I). Key to improving learning was also to develop teachers' understanding of the methods used: 'What I wanted to avoid was a kind of "tips for teachers" approach, they need to understand why do we do this' (Head, supporting school C, partnership 3, type I).

Many partnerships focused on developing assessment for learning: 'Research shows it works, and my experience as a leader shows it works. If you don't know where a child is, and where she can get to, how can you teach her? What we ask is: do you know enough about each child in your class?' (Head, supporting school E, partnership 5, type I). One way of improving assessment was developing better data systems and analysis: 'One of the key things for me is that we have put in place systems that allow us to drill down where they are in relation to where we think they should be. I know that has taken an enormous resource and time, but it's like a business, you can't run it without numbers' (Governor, supported school J, partnership 1, type I). Assessment for learning had to be embedded as a way of thinking and organising learning, rather than being a set of tips and tricks from a toolkit, which it can at times be reduced to: 'If you do that, what happens is teachers will just pick a toolkit randomly, but it will not be based on the child's actual learning and level. It's that constant AFL cycle, it doesn't stop' (Head, supported school O, partnership 6, type II).

Generating quick wins. While successful partnerships made fundamental changes to leadership and teaching, there was also a view that quick wins were needed to restore morale in the supported school and develop momentum and support for change, even if these interventions could be somewhat shallow. Typically such interventions focused on accountability systems such as inspection or KS2 results. 
Support in navigating the inspection process was mentioned by a number of interviewees: 'Being shown how to and what to and how to evidence things has been really useful, and has helped us come out of the category a lot quicker. There is no handbook that shows you how to deal with everything thrown at you. For example, we took one of our assistant heads and looked at how to prepare for an inspection' (Head, supported school K, partnership 2, type I), and in some cases mock inspections had been organised with the Local Authority to demonstrate change.

In many cases, there was a perceived need for immediate intervention to improve outcomes in the end of Key Stage 2 SAT's (end of primary school assessments). In the view of one headteacher (supported school $\mathrm{K}$, partnership 2, type I): 'Unfortunately we are judged on the SATs and nothing else, so you do need some quick fixes, which often means really frontloading support in Year 6'. This frequently entailed the teachers perceived as most effective being moved to teach in Year 6, or targeted support and exam preparation for Year 6 pupils. Some heads, however, eschewed such approaches, seeing them as too short-termist: 'You can't just go in there like the $S A S$, up the Year 6 results and leave, and let everything come back tumbling down. You have got to build capacity' (Head, supporting school F, partnership 6, type II). One deputy head saw long and short-term approaches as complementary, however: 'There's almost two jobs: one to quickly raise the standards, but then the second job of really building capacity before we leave. So it's not like, "hey the scores are up, isn't that great, now we'll go"' (Middle Manager, supporting school D, partnership 4, type I).

\section{What makes partnerships work?}

When looking at the factors that had facilitated successful partnership working, a number of key themes emerged. In particular, partnerships were more successful where they focused on a small number of key goals, established trust between the schools, used a phased approach to change, and developed a mutually beneficial relationship. Supporting schools needed to have the capacity to support, supported schools the openness to accept it.

Strong focus on a limited number of goals. In order to make the relationship work, partnerships needed to agree on clear shared goals and a common focus: 'You need to plan carefully first, and have a clear focus. That has to be shared, not just your views but those of the people you are working with as well. Sometimes we have had to go in without a clear focus and that has been the most challenging, because then they have no clear expectations, and they go who the hell are you to tell me what to do?' (Deputy Head, supporting school A, partnership 1, type I). A problem for schools in trouble is that they can become overloaded by various agencies and partners coming into the school with different improvement plans and emphases. This can make it hard to stay focused. For this reason, one supporting school which is involved in a lot of partnership work makes a point of ensuring they are the only 
organisation working intensively with the school 'Otherwise there are too many mixed messages' (Deputy Head, supporting school G, partnership 7, type II).

Trust and personal relationships. What many partnerships had to do first was build up trust, a fact frequently mentioned in the interviews: 'Trust. That's the biggest thing we're having to build up with school $N^{\prime}$ (Head, supporting school E, partnership 5, type I). Trust was seen as important not just in creating the conditions that would allow schools to accept support and work effectively together, but also in creating a culture of openness towards mistakes and weaknesses: 'Part of that is allowing people to make mistakes but then talking it through. That's important, because you will find in inadequate schools that people close their doors' (Deputy Head, supporting school D, partnership 4, type I). Supported schools needed to trust in the expertise of the supporting school. In one partnership staff in the supported school were feeling defensive regarding some of the findings from an LA review. The head of the supporting school therefore invited them to visit her school: 'You can come and see what we do, and if you think there is something to take from that, we can work together' (Head, supporting school C, partnership 3, type I). This was an effective way of building confidence in the expertise of the supporting school.

Trust is also about personal relationships, especially between headteachers and senior managers: 'You don't have to be best buddies, but you have to be on the same page' (Head, supporting school G, partnership 7, type II). Communication skills were frequently mentioned, but with a particular focus, among supporting schools, on listening: 'What you need to do is draw out from people what their issues are and what their needs are. You are not there to say this is how I run my school and this is how you should do it' (Head, supporting school E, partnership 5, type I). 'In schools we are so often expected to make an instant decision, so listening is really a skill I had to develop' (Deputy Head, supporting school H, partnership 8, type III).

Mutual benefits. It is an established research finding that partnerships benefit from the perception that each partner gains from the relationship, and it was striking how frequently heads from successful supporting schools mentioned the benefits of the partnership to their own school. These benefits were seen as taking two forms: the ability to learn from good practise in the supported school, and the opportunities for professional development emerging from the support work. Several heads made strong statements on the existence of good practise even in failing schools: 'You can always learn something. No matter what kind of school it is, we can always learn something and always bring something back' (Head, supporting school G, partnership 7, type II). 'In every school we've gone into we've found some absolute gems, some outstanding teachers' (Deputy Head, supporting school C, partnership 3, type I). 
Mentoring and coaching were seen as particularly powerful professional development activities for staff from supporting schools: 'Teacher $x$ was interested in a deputy headship, and supporting the school has really developed her in terms of mentoring and coaching' (Head, supporting school G, partnership 7, type II). Some teachers in the supporting schools commented on the ways their work in the partner school had helped them develop interpersonal skills: 'It really does teach you to get on with a wide range of people' (Teacher, supporting school B, partnership 2, type I).

For headteachers themselves supporting another school was motivating: 'I think being asked to help another school is the most exciting thing that can happen to a head' (Head, supporting school E, partnership 5, type I).

A phased approach. A phased approach was followed in the most effective partnerships. Support needed to be intensive in the early phases of partnership, but could often become increasingly hands-off over time as capacity in the supported school developed: 'I very rarely visit the school anymore, sometimes I phone and just ask 'is everything OK'. Both of us know that we are here if they need us, but ... It's a scaffolding there, gradually we have been taking down the top bits and there is only a little bit left there' (Head, supporting school B, partnership 2, type I). Within this phased approach, interim successes were important, especially if they came with external validation. For example, in one school an Ofsted report carried out after a period of partnership showed the supported school to be 'satisfactory'. 'This came as an enormous relief, it was a real boost' (Middle Manager, supported school K, partnership 2, type I).

Openness from the supported school. If partnership working is to be successful, the supporting school must be open to the intervention, especially at senior management level: 'If the head is not totally open, then how can it work' (Deputy Head, supported school M, partnership 4, type II). This openness has to be present among the whole staff: 'Even sometimes when people may think this is telling your granny to suck eggs, you need to bite your lips' (Teacher, supported school J, partnership 1, type I).

Where the head of the supported school had requested the support, things could more easily get off to a good start: 'It was us approaching the LA saying we wanted to work with school X, as I had already worked with the head there before I became head of this school. The biggest difference here was that we actually asked for the support. That was very powerful in talking with staff. What it was here was that we stabilised the ship, and then got school X to moor alongside and sail with us, rather than being done unto' (Head, supported school P, partnership 7, type II). Of course, this level of openness can be hard to achieve, especially where the head has been working in the school for a number of years, 'Because then it is easy to see having the support as failure, so there will be defensiveness' (Deputy Head, supported school R, partnership 9, type III). 
Seeing things work in practice was seen as potentially making a big difference. 'Sometimes people can think, this is more work, but then when they see the children more engaged, or behaving better, than that is what changes minds. The success in seeing children achieve changes minds when people are a bit sceptical' (Head, supported school K, partnership 2, type I). This again shows that it may be necessary to build short-term successes into the partnership planning process.

\section{Difficulties of partnership work}

As mentioned earlier, the school-to-school partnerships were not all uniformly successful. A number of difficulties were observed, including resistance and conflict in supported schools, and lack of capacity to support in the supporting schools.

Issues in supported schools. Unsurprisingly, while some supported schools were very open to being supported, resistance occurred in others: 'That did happen in school Y, where initially I felt I was batting my head against the brick wall. But then I got them to have a meeting here, and watch what we were doing, and then it changed. So I think showing them an example from your school may show them that you do know what you are talking about. If there is resistance and the school doesn't realise they need help then it won't work' (Head, supporting school E, partnership 5, type I). Successful building of trust and clear agreement on goals could help mitigate, but not in all cases solve these issues.

Difficulties also arose where there was significant conflict between teachers in the supported school. This could be very harmful to any attempts at improvement, and in some cases major staffing changes (up to $60 \%$ ) had to be implemented before improvement was possible.

For supported schools, there is always a danger of dependency developing, and partnership working therefore has to build independence in the supported school: ' $I$ can't be there all the time, it's got to be themselves taking the reins. You need to not do it for them, you need to develop the skills in them. That's where the coaching role comes in, where you are really just asking the right questions' (Deputy Head, supporting school G, partnership 7, type II).

A danger was that partnership was seen as a quick fix, to get schools out of trouble with little follow-through, and sometimes lack of time spent on activities could be a problem: 'I went in and we did the teaching and learning, and they improved. But then I went in to do the planning, and the teaching and learning kind of just went. They hadn't had time to embed it. So sometimes the support you think people need isn't really enough or what they really need' (Head, supporting school $\mathrm{H}$, partnership 8, type III).

Issues in supporting schools. A major issue for supporting schools is not to overload staff. There is a limit to the number of partnerships in which a school can sensibly 
be involved. As one governor said: 'I think if the head was involved with too many partners then it will start to impact negatively on the school' (Governor, supporting school A, partnership 1, type I). In some cases there had been issues in this respect: 'Some things went a bit awry. That push that the head put in wasn't fully there. We probably expected too much of our up and coming leaders' (Governor, supporting school $\mathrm{H}$, partnership 8, type III). If teachers were going to spend time outside of school, capacity needed to be built internally to deal with their absence: 'It's building capacity. Keeping an eye on the next generation coming up and developing them. We are also not afraid of creatively creating new posts if we see someone good. It's about talent spotting and growing from within' (Head, supporting school B, partnership 2, type II). This did have financial implications, however, and if not carefully managed there was a danger that partnership can have a negative impact on budgets in the supporting school.

Capacity in the supporting school. For support to be successful, supporting schools need to have sufficient capacity to engage in the intensive interventions mentioned above: 'You need to have the capacity to do it, otherwise you can almost be overwhelmed by it yourself (Deputy Head, supporting school G, partnership 7, type II). In some schools, therefore, leadership structures had been set-up where co-leaders were appointed to make sure there was no overreliance on the head if s/he spent time supporting partner schools: 'I know I can walk out of this door and it is not going to fall apart' (Head, supporting school C, partnership 3, type I). 'The head had to be confident that there was someone in charge when she was away who she could trust' (Deputy Head, supporting school D, partnership 4, type I).

The emphasis on teaching and learning in the partnerships meant that the supporting school staff needed to be knowledgeable on pedagogy and skilled in its use, and where coaching was used, coaching skills were important. Teachers in the supporting schools required support in these areas: 'They are monitored, and supported, and trained to give the support in the first place' (Head, supporting school B, partnership 2, type I).

Schools needed a clear sense of what they could and couldn't help with: 'It's also about knowing your own strengths and weaknesses, and what you can and cannot do. Also the strengths and weaknesses of your staff. You've got to know who can help who' (Deputy Head, supporting school F, partnership 6, type II). Sometimes this could mean rejecting requests for support: 'We are now turning away some other requests because this is such a big piece of work' (Head, supporting school B, partnership 2, type I).

The experience of the supporting leaders was also a factor: 'I have worked in many schools, and some of the schools I have taken on were failing. But once they have been turned around, then you can go on to help other schools' (Head, supporting school A, partnership 1, type I). 


\section{Discussion}

This study aimed to answer three key questions: can collaboration between high and low performing primary schools lead to an improvement in pupil attainment; what activities are related to effective collaboration between low and high performing primary schools; and what factors can explain any differences in effectiveness of collaboration between low and high performing primary schools?

The quantitative analyses, using a quasi-experimental approach, provide an overall positive response to the first question. There was clear evidence of an increase in pupil attainment, providing replication in the primary sector of results previously obtained in studies of secondary schools (Chapman \& Muijs, 2014), and confirmation of the theoretical support for collaboration as a form of school improvement. Of course, some caveats need to be taken into account. Quasi-experimental research is imperfect in terms of providing causal evidence, the lack of true randomisation leaving open the possibility of alternative explanations for differences between intervention and comparison groups, such as prior differences in leadership capacity. The study was also conducted in one particular local authority, which by definition limits generalisability of the findings, though the area is comparable to many similar urban LAs in England. Further replication will be necessary to test generalisability of these findings across the primary sector. And, of course, success was not uniform across partnerships, suggesting that this approach is by no means a panacea for school improvement.

In the case studies we were able to further probe some of the activities and factors associated with successful partnership, providing data relating to the second and third research questions. What was clear from these qualitative analyses was that successful partnership working is an intensive process, which requires active intervention in the key processes related to school outcomes: teaching, leadership and assessment (Chapman, Muijs, Reynolds, Sammons \& Teddlie, forthcoming). Many of these factors support what we already know from previous studies, such as the need for leadership support, mutual trust and goals, the need to focus on teaching and learning, and the development of capacity in the supporting and supported schools (e.g. Hadfield \& Chapman, 2009; Rudd et al., 2004; West, 2010). Others, however, reflect factors commonly reported in individual school improvement, but infrequently highlighted in the literature on collaboration, such such as the need to build in quick wins (e.g. Hopkins, Stringfield, Harris, \& Mackay, 2014). This study also points in particular to the potential power of very specific practices, such as coaching and mentoring, as part of collaborative work, and highlights the intensity required to make school-to-school support work, with all successful partnerships here reporting sustained hands-on engagement with supporting schools across both leaders and classroom teachers. In comparison to individual school improvement this study highlights a possible advantage of partnership in that it allows schools to more quickly develop capacity by building on the existing capacity and expertise in the supporting school, without the need for contracting in external organisations who may have a less direct understanding of schools, not least in their emotional 
and affective contexts. As such, collaboration may provide specific value added to school improvement efforts.

This study thus provides some support to theoretical perspectives on collaboration, albeit not equally strongly to all. Most clearly, collaboration here acted as a means of plugging structural holes through providing expertise that was not available in the school, for example on assessment for learning. Collaboration was, however, also a way in which schools connected with different world-views and experiences, as advocated in constructivist organisational theory. The latter is clear in the way supporting schools get supported school staff to observe and interact, in order to broaden their understanding of what is possible, but also, conversely, in the way supporting schools learn from practices that exist in supported schools. The statement that 'there are gems in every school we work with', made by the head of a supporting school, illustrates how confrontation with the reality of the other may modify perceptions of inadequacy and stark distinctions between types of schools (effective/ineffective). There was some link to Durkheimian theory, albeit mainly in the ways headteachers supported one another, with a sense of alienation and disconnect present in the embattled heads of some of the low performing schools mitigated by their collaboration with supporting heads. What was not strongly present was any notion of partnerships as new social movements, with only one partnership appearing primarily bottom-up, where the supported school head had requested support rather than having it brokered for them by the LA.

This study can be added to a growing body of research suggesting that collaboration can be a successful school improvement strategy, and that, in particular, collaboration between low and high performing schools can lead to improvements in attainment. In using a relatively rigorous methodology this study provides stronger evidence than most work in this field (in particular in primary schools), which has not tended to employ statistical matching to create comparison groups to study the relationships with pupil attainment. The word 'can' is important here, as it would be wrong to look at collaboration as the recipe for improvement. This is clearly not the case. Not only do we have evidence that many collaborations do not work, and that successful collaboration is a time and effort-intensive process that requires a range of conditions (trust, mutual benefits, capacity etc.) to be in place, but we also know that other approaches, such as addressing within school variation (Chapman et al., forthcoming) or working with external partners may be successful as well. Therefore, it is important to see school-to-school collaboration as a potentially powerful part of a menu of school improvement options, with the choice of approach tailored to circumstances, context and capacities in any given situation. An important issue here is that, in light of the limitations in capacity inherent in many failing schools, it may be necessary for external brokerage to aid in the search for appropriate improvement strategies, pointing to the importance of the existence of a middle tier between school and central government that may help put such brokerage in place. 


\section{Disclosure statement}

No potential conflict of interest was reported by the author.

\section{Notes on contributor}

Daniel Muijs is Professor of Education at the University of Southampton. He is an acknowledged expert in the fields of Educational and Teacher Effectiveness and quantitative research methods and is co-editor of the journal School Effectiveness and School Improvement. He has published widely in the areas of teacher and school effectiveness and improvement, educational leadership and research methods, and has a strong interest in the relationship between research, policy and practice.

\section{References}

Chapman, C. \& Allen, T. (2005). Partnerships for improvement: The specialist schools achievement programme. London: The Specialist Schools Trust.

Chapman, C. \& Muijs, D. (2013). Collaborative school turnaround: A study of the impact of school federations on student outcomes. Leadership and Policy in Schools, 12, 200-226.

Chapman, C. \& Muijs, D. (2014). Does school-to-school collaboration promote school improvement? A study of the impact of school federations on student outcomes. School Effectiveness and School Improvement, 25, 351-393.

Chapman, C., Muijs, D., Reynolds, D, Sammons, P. \& Teddlie, C. (forthcoming). The International handbook of educational effectiveness and improvement. London: Taylor \& Francis.

CUREE (2005). Systematic research review: The impact of networks on pupils, practitioners, organisations and the committees they serve. Nottingham: NCSL.

Hadfield, M. (2007). Co-leaders and middle leaders: The dynamic between leaders and followers in networks of schools. School Leadership and Management, 27, 259-283.

Hadfield, M. \& Chapman, C. (2009). Leading school-based networks. London: Routledge.

Hadfield, M., Jopling, M., Noden, C., O'Leary, D., \& Stott, A. (2006). What does the existing knowledge base tell us about the impact of networking and collaboration? A review of network-based innovations in education in the UK. Nottingham: National College for School Leadership.

Hall, J., Sylva, K., Sammons, P., Melhuish, E., Siraj-Blatchford, I., \& Taggart, B. (2013). Can preschool protect young children's cognitive and social development? Variation by center quality and duration of attendance? School Effectiveness and School Improvement, 24, 155-176.

Hopkins, D., Stringfield, S., Harris, A., Stoll, L., \& Mackay, T. (2014). School and system improvement: A state of the art review. School Effectiveness and School Improvement, 25, 257281.

Hutchings, M., Greenwood, C., Hollingworth, S., Mansaray, A., Rose, A., \& with Minty, S. \& Glass, K. (2012). Evaluation of the City Challenge programme. London: Department for Education.

Huxham, C. \& Vangen, S. (2000). Ambiguity, complexity and dynamics in the membership of collaboration. Human Relations, 53, 771-806.

Lieberman, A. (2000). Networks as learning communities: Shaping the future of teacher development. Fournal of Teacher Education, 51, 221-227.

Lindsay, G., Harris, A., Chapman, C., \& Muijs, D. (2005). School federations. Preliminary report to the DfES. Coventry: University of Warwick. 


\section{D. Muijs}

Lindsay, G., Muijs, D., Harris, A., Chapman, C., Arweck, E., \& Goodall, J. (2007). Final report of the evaluation of the federations policy. Project report. London: Department for Children, Schools and Families.

Miles, M. \& Huberman, A. (1994). Qualitative data analysis. Thousand Oaks, CA: Sage.

Muijs, D., Chapman, C., Ainscow, M., \& West, M. (2011). Networking and collaboration in education. Dordrecht: Springer.

Muijs, D., West, M., \& Ainscow, M. (2010). Why network? Theoretical perspectives on networking and collaboration between schools. School Effectiveness and School Improvement, 21, 5-26.

Rudd, P., Lines, A., Schagen, S., Smith, S., \& Reakes, A. (2004). Partnership approaches to sharing best practice. Slough: NFER.

Sammons, P. (2010). Do the benefits of pre-school last? In K. Sylva, E. Melhuish, P. Sammons, I. Siraj-Blatchford \& B. Taggart (Eds.), Early childhood matters: Evidence from the Effective Pre-school and Primary Education Project. New York, NY: Routledge.

Schwandt, T. A. \& Halpern, E. S. (1988). Linking auditing and metaevaluation: Enhancing quality in applied research. London: Sage.

Strand, S. \& Demie, F. (2002). Pupil mobility, attainment and progress in primary school. British Educational Research fournal, 32, 551-568.

West, M. (2010). School-to-school cooperation as a strategy for improving student outcomes in challenging contexts. School Effectiveness and School Improvement, 21, 93-112.

Wohlstetter, P., Malloy, C. L., Chau, D., \& Polhemus, J. L. (2003). Improving schools through networks: A new approach to urban school reform. Educational Policy, 19, 643-672. 